\title{
Second Primary Cancers After Liver, Gallbladder and Bile Duct Cancers, and These Cancers as Second Primary Cancers
}

\begin{abstract}
Guoqiao Zheng, ${ }^{1-3}$
Kristina Sundquist, ${ }^{3-5}$

Jan Sundquist, (1D ${ }^{3-5}$

Tianhui Chen, ${ }^{6}$ Asta Försti, ${ }^{1,47,8}$

Akseli Hemminki, (D) 9,10

Vaclav Liska, ${ }^{11,12}$

Kari Hemminki (1D) ${ }^{1,2,4,12}$

'Division of Molecular Genetic Epidemiology, German Cancer Research Center (DKFZ), Heidelberg, D-69|20, Germany; ${ }^{2}$ Division of Cancer Epidemiology, German Cancer Research Center (DKFZ), Heidelberg, D-69120, Germany; ${ }^{3}$ Center for Primary Health Care Research, Lund University, Malmö, 205 02, Sweden; ${ }^{4}$ Department of Family Medicine and Community Health, Department of Population Health Science and Policy, Icahn School of Medicine at Mount Sinai, New York, NY, USA; ${ }^{5}$ Center for Communitybased Healthcare Research and Education (CoHRE), Department of Functional Pathology, School of Medicine, Shimane University, Matsue, Japan; ${ }^{6}$ Department of Cancer Prevention, Cancer Hospital of the University of Chinese Academy of Sciences (Zhejiang Cancer Hospital), Institute of Basic Medicine and Cancer, Chinese Academy of Sciences, Hangzhou, 310022 , People's Republic of China; ${ }^{7}$ Hopp Children's Cancer Center (KiTZ), Heidelberg, Germany; ${ }^{8}$ Division of Pediatric Neurooncology, German Cancer Research Center (DKFZ), German Cancer Consortium (DKTK), Heidelberg, Germany; ${ }^{9}$ Cancer Gene Therapy Group, Translational Immunology Research Program, University of Helsinki, Helsinki, Finland; ${ }^{10}$ Comprehensive Cancer Center, Helsinki University Hospital, Helsinki, Finland; " Department of Surgery, University Hospital, School of Medicine in Pilsen, Pilsen, Czech Republic; ${ }^{12}$ Biomedical Center, Faculty of Medicine and Biomedical Center in Pilsen, Charles University in Prague, Pilsen, 30605, Czech Republic
\end{abstract}

Correspondence: Kari Hemminki Biomedical Center, Faculty of Medicine and Biomedical Center in Pilsen, Charles University, Pilsen, 30605, Czech Republic

Tel +496221421800

Fax +496221422203

Email K.Hemminki@dkfz.de
Background: Second primary cancers (SPCs) are important clinically as they may negatively influence patient survival and they may tell about therapeutic side effects and general causes of cancer. Population-based literature concerning SPCs after hepatobiliary cancers is limited and here we assess risks of SPCs after hepatocellular cancer (HCC), and cancers of the gallbladder, bile ducts and ampulla of Vater. In reverse order, we consider the risk of hepatobiliary cancers as SPCs after any cancer.

Methods: We used standardized incidence ratios (SIRs) to estimate bidirectional relative risks of subsequent cancers associated with hepatobiliary cancers. Cancer diagnoses were obtained from the Swedish Cancer Registry from years 1990 through 2015.

Results: We identified 9997 primary HCCs, 1365 gallbladder cancers and 4721 bile duct cancers. After HCC, risks of four SPCs were increased: gallbladder (SIR $=4.38 ; 95 \%$ confidence interval $1.87-8.67)$, thyroid $(4.13 ; 1.30-9.70)$, kidney $(2.92 ; 1.66-4.47)$ and squamous cell skin $(1.55 ; 1.02-2.26)$ cancers. In reverse order, HCC as SPC, in addition to the above cancers, associations included upper aerodigestive tract, esophageal, small intestinal and bladder cancers and non-Hodgkin lymphoma. For gallbladder and bile duct cancers, associations were found with small intestinal and pancreatic cancers.

Conclusion: The results suggested that HCC is associated with two types of SPC, one related to shared environmental risk factors, such as alcohol, exemplified by upper aerodigestive tract and esophageal cancer, and the other related to immune dysfunction, exemplified by squamous cell skin cancer. SPCs associated with gallbladder and bile duct cancers suggest predisposition to mutations in the mismatch repair gene MLH1.

Keywords: cancer incidence, relative risk, second primary cancer, cancer etiology, hepatobiliary cancer

\section{Introduction}

Primary hepatobiliary cancers include hepatocellular carcinoma (HCC), gallbladder cancer and cancers of the extrahepatic (and intrahepatic) bile ducts (biliary tract) and of the ampulla of Vater. ${ }^{1,2}$ The incidence of these cancers show large international variation, which correlates with the known risk factors that are best characterized for HCC: chronic infection by hepatitis $\mathrm{B}$ or $\mathrm{C}$ virus, cholangiocarcinogenic liver flukes, ingestion of aflatoxin B1 mycotoxin, non-alcoholic metabolic liver disease, alcoholinduced or other types of liver cirrhosis and smoking. ${ }^{1,3-7}$ The international variation in incidence is less dramatic for gallbladder cancer, for which gallstones, carcinogen exposure, Salmonella enterica serovar Typhi and Helicobacter pylori infection and 
biliary cysts and other structural abnormalities are known risk factors. ${ }^{1,8,9}$ For female gallbladder cancer, obesity is a strong risk factor, which is also associated with gallstones. ${ }^{10}$ In addition to environmental risk factors, increased familial risk suggests a role for genetic factors in these cancers. ${ }^{11}$ Familial aggregation of HCC has been observed in high-risk areas and chronic hepatitis B carriers, but to what extent the results show shared environment or inherited susceptibility remains unknown. ${ }^{12,13} \mathrm{HCC}$ is a manifestation in some rare inherited metabolic diseases, such as porphyria cutanea tarda and inherited hemochromatosis. ${ }^{1}$ All hepatobiliary cancers are increased in autoimmune disease patients thus indicating the contribution of immune dysfunction in their etiology; the highest risks were found after primary biliary cirrhosis and autoimmune hepatitis. ${ }^{14,15}$ Biliary tract and gallbladder cancers manifest in hereditary nonpolyposis colorectal cancer (HNPCC, Lynch syndrome), particularly in mutation carriers of the gene MLH1. ${ }^{16}$ Northern Europe is a low-risk area for hepatobiliary cancers, which is also confirmed in cancer risks of the local immigrants. ${ }^{17}$ The age-standardized incidence for HCC in 2008 for Sweden was estimated at 4.6/100,000 for men and 2.0/100,000 for women while the rates for gallbladder cancer were 1.8 and $2.9 / 100,000$, respectively. ${ }^{18}$ The incidence of bile duct and ampulla Vater cancers were each about half of the rates for gallbladder cancer. ${ }^{11}$ Survival in all these cancers is generally poor. ${ }^{18}$

Second primary cancers (SPCs) are an increasing type of cancer because overall survival in cancer is increasing and the likelihood of being diagnosed with another cancer is thus increasing. ${ }^{19}$ Consequently, in cancers of poor survival, SPCs are less common and also reporting of SPCs may not be complete because of the concerns about the first primary cancer (FPC). ${ }^{20}$ Population-based literature on SPCs after hepatobiliary cancers is not extensive, probably because of the poor survival. The relative risk of SPCs after HCC is low but in those surviving at least two years, an increase was found for second stomach, biliary tract, bladder and kidney cancers. ${ }^{20,21}$ We have noted that the risk for $\mathrm{HCC}$ was increased when diagnosed as SPC after FPC compared to the risks of SPCs following $\mathrm{HCC}^{22,23}$ We decided therefore to examine systematically and bidirectionally the risks of any cancer after hepatobiliary cancers and of hepatobiliary cancers as SPC after any cancer. The hepatobiliary cancers considered were HCC and cancers of the gallbladder, bile ducts and ampulla of Vater, identified from the nationwide Swedish Cancer Registry.

\section{Materials and Methods}

We used nationwide data in this paper derived from Statistics Sweden and the Swedish Cancer Register. Data were delivered to us in a pseudonymized format. We have no access to any keys between the pseudonymized data delivered to us and personal information, such as name, address, or personal ID numbers. The International Classification of Diseases revision 7 (ICD-7 and later revisions) distinguishes four groups of primary liver and biliary tract tumors by organ sites under code 155: liver (ICD-7 code 155.0), gallbladder (155.1), bile ducts (155.2 through 155.9) and ampulla of Vater (155.3) as part of bile ducts. These and other cancer data were retrieved from the Swedish Cancer Registry covering years 1990 through 2015. The other cancers include any of 23 common male and 24 female FPCs or SPCs. Patients were followed up from 1990 onward from the diagnosis of FPC until the end of 2015 or diagnosis of SPC, immigration or death, whichever came earliest. Only discordant (different) FPC-SPC pairs were included. Upper aerodigestive tract (UAT) included lip, oral cavity, pharynx and larynx. Kidney cancer only included renal cell carcinoma, though renal pelvic and ureteral cancers were considered. However, case numbers were few and not reported. For skin cancer, only melanoma and squamous cell carcinoma were included.

Standardized incidence ratios (SIRs) for SPC were estimated through the observed number of SPCs divided by the expected number of cases. The expected number of cancer cases was estimated by the followed person-years after first primary cancer diagnosis, multiplied by the incidence of the same cancer as FPC in the general population. The estimation was done for both sexes combined or separately, and adjusted for age, calendar year, place of residence and socioeconomic factors. The $95 \%$ confidence interval $(95 \% \mathrm{CI})$ for SIRs were calculated by assuming the Poisson distribution. The data analysis for this paper was generated using SAS software, Version 9.4 of the SAS System for Windows. Copyright (C) 2016 SAS Institute Inc., Cary, NC, USA.

In interpreting the findings, we try to emphasize their clinical importance by considering the magnitude of the risk estimate and its precision, ie, the width of Cl. ${ }^{24}$ According to this convention, we do not refer to "statistical significance" when CI does not contain the null value. However, as the study includes close to 500 SIRs we help the reader to focus on the results with potential clinical importance by bolding SIRs when the 95\% CIs do not 
Table I Characteristics of the Cancer Patients Included in the Study

\begin{tabular}{|c|c|c|c|c|c|c|c|c|c|}
\hline \multicolumn{2}{|l|}{ Characteristics } & \multicolumn{2}{|c|}{ Hepatocellular Carcinoma } & \multicolumn{2}{|c|}{ Gallbladder Cancer } & \multicolumn{2}{|c|}{ Bile Duct Cancer } & \multicolumn{2}{|c|}{ Other Cancers } \\
\hline \multicolumn{2}{|c|}{ Median Age at Diagnosis (IQR) } & \multicolumn{2}{|c|}{$71(62-78)$} & \multicolumn{2}{|c|}{$73(65-80)$} & \multicolumn{2}{|c|}{$72(64-80)$} & \multicolumn{2}{|c|}{$69(59-78)$} \\
\hline & & $\mathbf{N}$ & $\%$ & $\mathbf{N}$ & $\%$ & $\mathbf{N}$ & $\%$ & $\mathbf{N}$ & $\%$ \\
\hline \multirow{5}{*}{ Year of diagnosis } & $1990-1995$ & 2285 & 22.9 & 1883 & 35.7 & 1176 & 24.9 & 213,842 & 20.1 \\
\hline & $1996-2000$ & 1698 & 17.0 & 1100 & 20.9 & 896 & 19.0 & 187,159 & 17.6 \\
\hline & $200 I-2005$ & 1717 & 17.2 & 858 & 16.3 & 823 & 17.4 & 205,822 & 19.4 \\
\hline & $2006-2010$ & 1806 & 18.1 & 715 & 13.6 & 817 & 17.3 & 218,218 & 20.5 \\
\hline & $2011-2015$ & 2491 & 24.9 & 721 & 13.7 & 1009 & 21.4 & 238,755 & 22.4 \\
\hline \multirow[t]{2}{*}{ Gender } & Male & 6485 & 64.9 & 1365 & 25.9 & 2252 & 47.7 & 553,389 & 52.0 \\
\hline & Female & 3512 & 35.1 & 3912 & 74.1 & 2469 & 52.3 & 510,407 & 48.0 \\
\hline \multirow[t]{4}{*}{ Place of residence } & Big cities & 4736 & 47.4 & 1973 & 37.4 & 2127 & 45.1 & 496,423 & 46.7 \\
\hline & South Sweden & 3019 & 30.2 & 2151 & 40.8 & 1677 & 35.5 & 363,923 & 34.2 \\
\hline & North Sweden & 2185 & 21.9 & 1146 & 21.7 & 910 & 19.3 & 200,655 & 18.9 \\
\hline & Unspecified & 57 & 0.6 & 7 & 0.1 & 7 & 0.2 & 2795 & 0.3 \\
\hline \multirow[t]{6}{*}{ Socioeconomic status } & Agriculture & 64 & 0.6 & 49 & 0.9 & 58 & 1.2 & 43,524 & 1.3 \\
\hline & Private & 348 & 3.5 & 117 & 2.2 & 157 & 3.3 & 66,090 & 3.4 \\
\hline & Professional & 502 & 5.0 & 213 & 4.0 & 263 & 5.6 & 103,703 & 7.5 \\
\hline & Blue collar & 1376 & 13.8 & 688 & 13.0 & 769 & 16.3 & 339,808 & 19.9 \\
\hline & Worker & 2138 & 21.4 & 1035 & 19.6 & 1005 & 21.3 & 442,109 & 22.7 \\
\hline & Other & 5569 & 55.7 & 3175 & 60.2 & 2469 & 52.3 & 68,562 & 45.3 \\
\hline All & & 9997 & 100 & 5277 & 100 & 4721 & 100 & $1,063,796$ & 100 \\
\hline
\end{tabular}

Abbreviation: IQR, inter quartile range.

overlap with 1.00 . To simplify the tables, cancer sites were not reported if less than five cases were found in Table 1 column "HCC as SPC"; however, all hepatobiliary sites were kept. The total numbers "All" included also the deleted sites.

\section{Results}

Characteristics of the study population are described in Table 1. During the follow-up period of 1990 to 2015, we identified $9997 \mathrm{HCC}, 64.9 \%$ male, median diagnostic age 71 years (inter quartile range IQR, 62-78), 5277 gallbladder cancers $25.9 \%$ male, median diagnostic age 73 years (IQR,65-80) and 4721 bile duct cancers $47.7 \%$ male, median diagnostic age 72 years (IQR,64-80). Among bile duct cancers, 1025 Ampulla of Vater cancers (56.2\% male) were identified and the median diagnostic age was 72 years (IQR, 63-79). The total number of other cancers considered was $1,056,493$ (52.0\% male). The median follow-up time was three $(0-11)$ months for SPC after HCC, three (1-10) months after gallbladder and five (1-15) months after bile duct cancer. For hepatobiliary cancers as SPC, the corresponding times were 37 (9-97) months for HCC, 36 (9-96) months for gallbladder and 36 (9-96) months for bile duct cancer.

SIRs for SPCs of both sexes associated with HCC are shown in Table 2. Based on 297 cases, the overall risk for SPCs after HCC was not increased (SIR 1.04). Risks for four SPCs were increased: gallbladder (4.38), thyroid (4.13), kidney (2.92) and skin squamous cell (SCC, 1.55) cancers. In reverse order, HCC as SPC, the overall SIR was increased to 1.19 with 1012 cases. Risks for gallbladder (2.88), kidney (2.14) and skin SCC (1.45) were bidirectionally increased, as was thyroid cancer at borderline (2.13). Additional SIRs were increased for UAT, esophageal, small intestinal and bladder cancers and NHL. For kidney cancer, results were assessed separately for right and left kidney (the right kidney is located in the backside of the liver) but the case numbers were too small to be conclusive. In this and subsequent tables, some associations with breast and prostate cancers were decreased. Sex-specific data are shown in Supplementary Tables 1 and $\underline{2}$. Male data of HCC with many more cases drove the results.

Similar analysis is shown for gallbladder cancer in Table 3. Only risks for HCC (2.88), bile duct (5.05) and kidney (3.04) cancers were increased as SPCs. In reverse 
Table 2 Risks of SPCs After Hepatocellular Carcinoma (HCC) and Those of HCC as SPCs

\begin{tabular}{|c|c|c|c|c|c|c|c|c|}
\hline \multirow{3}{*}{$\begin{array}{l}\text { Cancer Site } \\
\text { UAT }\end{array}$} & \multicolumn{4}{|c|}{ SPC After HCC } & \multicolumn{4}{|c|}{$\mathrm{HCC}$ as SPC } \\
\hline & \multirow{2}{*}{$\mathbf{N}$} & \multirow{2}{*}{$\begin{array}{ll}\text { SIR } \\
1.19\end{array}$} & \multicolumn{2}{|l|}{$95 \% \mathrm{Cl}$} & \multirow{2}{*}{$\begin{array}{l}\mathbf{N} \\
40\end{array}$} & \multirow{2}{*}{$\begin{array}{ll}\text { SIR } & \\
& 2.13\end{array}$} & \multicolumn{2}{|l|}{$95 \% \mathrm{Cl}$} \\
\hline & & & 0.51 & 2.36 & & & 1.52 & 2.91 \\
\hline Esophagus & 3 & 0.82 & 0.15 & 2.43 & 11 & 2.43 & 1.21 & 4.36 \\
\hline Stomach & 7 & 0.76 & 0.30 & 1.58 & 18 & 1.22 & 0.72 & 1.93 \\
\hline Small intestine & 3 & 2.12 & 0.40 & 6.28 & 10 & 3.01 & 1.44 & 5.56 \\
\hline CRC & 38 & 0.99 & 0.70 & 1.36 & 117 & 1.15 & 0.95 & 1.38 \\
\hline Gallbladder & 8 & 4.38 & 1.87 & 8.67 & 6 & 2.88 & 1.04 & 6.31 \\
\hline Bile ducts & 2 & 1.13 & 0.11 & 4.16 & 4 & 1.84 & 0.48 & 4.77 \\
\hline Pancreas & 14 & 1.58 & 0.86 & 2.65 & 7 & 0.84 & 0.33 & 1.75 \\
\hline Lung & 27 & 0.94 & 0.62 & 1.36 & 44 & 1.22 & 0.89 & 1.64 \\
\hline Breast & 9 & 0.46 & 0.21 & 0.88 & 93 & 1.08 & 0.87 & 1.32 \\
\hline Endometrium & 6 & 1.16 & 0.42 & 2.54 & 26 & 1.18 & 0.77 & 1.73 \\
\hline Ovary & 4 & 1.36 & 0.35 & 3.51 & 7 & 0.81 & 0.32 & 1.68 \\
\hline Prostate & 40 & 0.50 & 0.36 & 0.68 & 232 & 0.80 & 0.70 & 0.91 \\
\hline Kidney & 16 & 2.92 & 1.66 & 4.75 & 32 & 2.14 & 1.46 & 3.02 \\
\hline Left & 4 & 1.76 & 0.46 & 4.54 & 13 & 2.13 & 1.13 & 3.65 \\
\hline Right & 10 & 3.44 & 0.89 & 8.89 & 10 & 1.70 & $0.8 I$ & 3.13 \\
\hline Bladder & 17 & 0.95 & 0.55 & 1.52 & 87 & 1.64 & 1.31 & 2.02 \\
\hline Melanoma & 4 & 0.42 & 0.11 & 1.09 & 25 & 0.74 & 0.48 & 1.09 \\
\hline Skin SCC & 27 & 1.55 & 1.02 & 2.26 & 58 & 1.45 & 1.10 & 1.88 \\
\hline Nervous system & 9 & 1.52 & 0.69 & 2.89 & 14 & 0.85 & 0.46 & 1.43 \\
\hline Thyroid & 5 & 4.13 & 1.30 & 9.70 & 9 & 2.13 & 0.97 & 4.07 \\
\hline Endocrine & 7 & 2.25 & 0.89 & 4.65 & 22 & 1.46 & 0.91 & 2.21 \\
\hline $\mathrm{NHL}$ & 14 & 1.36 & 0.74 & 2.29 & 41 & 1.58 & 1.14 & 2.15 \\
\hline Myeloma & 4 & 0.89 & 0.23 & 2.30 & 12 & 1.19 & 0.61 & 2.08 \\
\hline Leukemia & 3 & 0.33 & 0.06 & 0.98 & 21 & 0.99 & 0.61 & 1.51 \\
\hline All & 297 & 1.04 & 0.92 & 1.16 & 1012 & 1.19 & 1.12 & 1.27 \\
\hline
\end{tabular}

Note: Bolding shows that the $95 \% \mathrm{Cl}$ does not overlap with 1.00 .

Abbreviations: $\mathrm{N}$, patient number; SIR, standardized incidence ratio; $95 \% \mathrm{Cl}, 95 \%$ confidence interval; SPC, second primary cancer; UAT, upper aerodigestive tract; CRC, colorectal cancer; HCC, hepatocellular carcinoma; NHL, non-Hodgkin lymphoma.

order, gallbladder cancer as SPC, associations were found for small intestinal cancer (3.64) and HCC (4.38). Sex-specific results are shown in Supplementary Tables 1 and 2 .

Table 4 shows results for bile duct cancer. The SIR for pancreatic cancer was increased to 2.80 as SPC. In the reverse order, risk of bile duct cancer was increased after small intestinal (3.73) and gallbladder (5.05) cancers. Sex- specific data showed that the results were driven by male data, as no significant associations were noted for women (Supplementary Tables 1 and 2). Risks of both small intestinal and pancreatic cancers were bidirectionally increased in men; small intestinal cancer as SPC, SIR 6.51 and in reverse order SIR 5.94; pancreas cancer as SPC, SIR 3.07 and in reverse order SIR 3.18. 
Table 3 Risks of SPCs After Gallbladder Cancer and Those of Gallbladder Cancer as SPC

\begin{tabular}{|c|c|c|c|c|c|c|c|c|}
\hline \multirow{3}{*}{$\begin{array}{l}\text { Cancer Site } \\
\text { UAT }\end{array}$} & \multicolumn{4}{|c|}{ SPC After Gallbladder Cancer } & \multicolumn{4}{|c|}{ Gallbladder Cancer as SPC } \\
\hline & \multirow{2}{*}{$\mathbf{N}$} & \multirow{2}{*}{$\begin{array}{ll}\text { SIR } & \\
& 0.34\end{array}$} & \multicolumn{2}{|l|}{$95 \% \mathrm{Cl}$} & \multirow{2}{*}{$\begin{array}{l}\mathbf{N} \\
6\end{array}$} & \multirow{2}{*}{$\begin{array}{ll}\text { SIR } & \\
& 0.86\end{array}$} & \multicolumn{2}{|l|}{$95 \% \mathrm{Cl}$} \\
\hline & & & 0 & 1.94 & & & 0.31 & 1.89 \\
\hline Esophagus & I & 0.65 & 0 & 3.72 & 0 & & & \\
\hline Stomach & 7 & 1.38 & 0.55 & 2.86 & 6 & 0.86 & 0.31 & 1.88 \\
\hline Small intestine & 3 & 3.6 & 0.68 & 10.6 & 6 & 3.64 & 1.31 & 7.98 \\
\hline CRC & 19 & 0.82 & 0.50 & 1.29 & 44 & 0.85 & 0.61 & 1.14 \\
\hline $\mathrm{HCC}$ & 6 & 2.88 & 1.04 & 6.31 & 8 & 4.38 & 1.87 & 8.67 \\
\hline Bile ducts & 6 & 5.05 & 1.82 & 11.06 & 2 & 1.71 & 0.16 & 6.27 \\
\hline Pancreas & 4 & 0.70 & 0.18 & 1.80 & 9 & 1.91 & 0.87 & 3.65 \\
\hline Lung & 7 & 0.49 & 0.19 & 1.01 & 9 & 0.56 & 0.25 & 1.07 \\
\hline Breast & 14 & 0.56 & 0.30 & 0.94 & 76 & 0.83 & 0.66 & 1.04 \\
\hline Endometrium & 6 & 0.85 & 0.31 & 1.87 & 27 & 1.11 & 0.73 & 1.62 \\
\hline Ovary & 7 & 1.71 & 0.68 & 3.54 & 9 & 0.93 & 0.42 & 1.78 \\
\hline Prostate & 15 & 0.78 & 0.44 & 1.30 & 39 & 0.61 & 0.44 & 0.84 \\
\hline Kidney & 9 & 3.04 & 1.38 & 5.80 & 4 & 0.56 & 0.15 & 1.46 \\
\hline Left & 4 & 3.44 & 0.90 & 8.90 & I & 0.37 & 0 & 2.11 \\
\hline Right & 4 & 3.44 & 0.89 & 8.89 & 2 & 0.76 & 0.07 & 2.79 \\
\hline Bladder & 5 & 0.7 & 0.22 & 1.65 & 16 & 0.89 & 0.51 & 1.45 \\
\hline Melanoma & 4 & 0.79 & 0.21 & 2.05 & 14 & 0.89 & 0.48 & 1.49 \\
\hline Skin SCC & 6 & 0.59 & 0.21 & 1.29 & 19 & 0.97 & 0.59 & 1.52 \\
\hline Nervous system & 2 & 0.54 & 0.05 & 1.99 & 7 & 0.75 & 0.30 & 1.56 \\
\hline Thyroid & I & 1.10 & 0 & 6.32 & 0 & & & \\
\hline Endocrine & 1 & 0.41 & 0 & 2.33 & 9 & 0.86 & 0.39 & 1.65 \\
\hline $\mathrm{NHL}$ & 1 & 0.17 & 0 & 0.98 & 10 & 0.79 & 0.38 & 1.46 \\
\hline Myeloma & 0 & & & & 2 & 0.39 & 0.04 & 1.45 \\
\hline Leukemia & 4 & 0.80 & 0.21 & 2.07 & II & 1.12 & 0.55 & 2.01 \\
\hline All & 143 & 0.88 & 0.75 & 1.04 & 351 & 0.86 & 0.77 & 0.95 \\
\hline
\end{tabular}

Note: Bolding shows that the $95 \% \mathrm{Cl}$ does not overlap with 1.00 .

Abbreviations: N, patient number; SIR, standardized incidence ratio; $95 \% \mathrm{Cl}, 95 \%$ confidence interval; SPC, second primary cancer; UAT, upper aerodigestive tract; CRC, colorectal cancer; HCC, hepatocellular carcinoma; NHL, non-Hodgkin lymphoma.

Ampulla of Vater cancer was included as part of the above bile duct cancer. When it was considered separately, the SIR for pancreatic cancer was increased as SPC to 4.27 (N=7, 95\% CI 1.69-2.93). Ampulla of Vater cancer as SPC was associated with small intestinal (SIR 8.59, N=3, 95\% CI 1.62-25.42) and breast cancers $(1.95,24$, $1.25-2.90)$.

\section{Discussion}

The incidence in hepatobiliary cancers is low in Northern Europe compared to the high-risk areas in the world, most likely due to the lower level of risk factors. ${ }^{1,25}$ In Sweden, somewhat over $60 \%$ of the HCC patients had an underlying liver disease, of which $48 \%$ was HCV and $41 \%$ alcohol; median survival was 1.2 years. ${ }^{25}$ In the interpretation of the 
Table 4 Risks of SPCs After Bile Duct Cancer and That of Bile Ductal Cancer as SPC

\begin{tabular}{|c|c|c|c|c|c|c|c|c|}
\hline \multirow{3}{*}{$\begin{array}{l}\text { Cancer Site } \\
\text { UAT }\end{array}$} & \multicolumn{4}{|c|}{ SPC After Bile Duct Cancer } & \multicolumn{4}{|c|}{ Bile Duct Cancer as SPC } \\
\hline & \multirow{2}{*}{$\mathbf{N}$} & \multirow{2}{*}{$\begin{array}{ll}\text { SIR } & \\
& 0.58\end{array}$} & \multicolumn{2}{|l|}{$95 \% \mathrm{Cl}$} & \multirow{2}{*}{$\frac{\mathbf{N}}{11}$} & \multirow{2}{*}{$\begin{array}{ll}\text { SIR } & \\
& 1.37\end{array}$} & \multicolumn{2}{|l|}{$95 \% \mathrm{Cl}$} \\
\hline & & & 0.05 & 2.13 & & & 0.68 & 2.46 \\
\hline Esophagus & 0 & & & & I & 0.55 & 0 & 3.12 \\
\hline Stomach & 6 & 1.22 & 0.44 & 2.67 & 2 & 0.30 & 0.03 & 1.11 \\
\hline Small intestine & 3 & 3.67 & 0.69 & 10.9 & 6 & 3.73 & 1.34 & 8.17 \\
\hline CRC & 19 & 0.84 & 0.51 & 1.32 & 61 & 1.20 & 0.92 & 1.54 \\
\hline $\mathrm{HCC}$ & 4 & 1.84 & 0.48 & 4.77 & 2 & 1.13 & 0.11 & 4.16 \\
\hline Gallbladder & 2 & 1.71 & 0.16 & 6.27 & 6 & 5.05 & 1.82 & II.1 \\
\hline Pancreas & 14 & 2.80 & 1.53 & 4.71 & 8 & 2.09 & 0.89 & 4.13 \\
\hline Lung & 9 & 0.59 & 0.27 & 1.13 & 9 & 0.58 & 0.26 & 1.10 \\
\hline Breast & 15 & 0.93 & 0.52 & 1.54 & 80 & 1.25 & 0.99 & 1.55 \\
\hline Endometrium & 2 & 0.46 & 0.04 & 1.68 & 21 & 1.25 & 0.77 & 1.91 \\
\hline Ovary & 4 & 1.66 & 0.43 & 4.30 & 2 & 0.32 & 0.03 & 1.18 \\
\hline Prostate & 27 & 0.70 & 0.46 & 1.02 & 74 & 0.68 & 0.53 & 0.85 \\
\hline Kidney & 6 & 2.03 & 0.73 & 4.45 & 7 & 1.01 & 0.40 & 2.09 \\
\hline Left & 5 & 4.09 & 1.29 & 9.61 & 3 & 1.07 & 0.20 & 3.16 \\
\hline Right & I & 0.83 & 0 & 4.74 & 3 & 1.10 & 0.21 & 3.27 \\
\hline Bladder & 3 & 0.32 & 0.06 & 0.95 & 27 & 1.19 & 0.78 & 1.73 \\
\hline Melanoma & 3 & 0.54 & 0.10 & 1.61 & 10 & 0.59 & 0.28 & 1.09 \\
\hline Skin SCC & 6 & 0.55 & 0.20 & 1.20 & 23 & 1.07 & 0.68 & 1.61 \\
\hline Nervous system & 2 & 0.6 & 0.06 & 2.21 & 5 & 0.60 & 0.19 & 1.41 \\
\hline Thyroid & 2 & 2.72 & 0.26 & 10.0 & I & 0.44 & 0 & 2.51 \\
\hline Endocrine & 1 & 0.50 & 0 & 2.89 & 8 & 0.93 & 0.40 & 1.84 \\
\hline $\mathrm{NHL}$ & 3 & 0.52 & 0.10 & 1.53 & 14 & 1.13 & 0.62 & 1.90 \\
\hline Myeloma & 0 & & & & 5 & 1.05 & 0.33 & 2.48 \\
\hline Leukemia & 4 & 0.78 & 0.20 & 2.01 & 13 & 1.29 & 0.68 & 2.21 \\
\hline All & 147 & 0.88 & 0.75 & 1.04 & 420 & 1.01 & 0.92 & 1.12 \\
\hline
\end{tabular}

Note: Bolding shows that the $95 \% \mathrm{Cl}$ does not overlap with 1.00 .

Abbreviations: $\mathrm{N}$, patient number; SIR, standardized incidence ratio; $95 \% \mathrm{Cl}, 95 \%$ confidence interval; SPC, second primary cancer; UAT, upper aerodigestive tract; CRC, colorectal cancer; HCC, hepatocellular carcinoma; NHL, non-Hodgkin lymphoma.

present results, we need to consider survival differences of these cancers, and as hepatobiliary cancers have poor survival, we observed far more cases of these cancers as SPCs compared to other cancers following hepatobiliary cancers; this, in turn, is related to the statistical power for finding an association. We observed decreased risks for some SPCs, for breast cancer only as SPC and for prostate cancer as FPC and SPC. The likely reason is the reporting bias of SPCs after fatal or old age FPCs. ${ }^{20,26}$ The fact that for breast cancer it was observed only as a SPC shows one of the advantages of the bidirectional analysis.

The present results with increased risks of HCC after UAT, esophageal, kidney and bladder cancers suggest a role for the shared risk factors of alcohol consumption and smoking. ${ }^{7}$ 
$\mathrm{HCV}$ is also a risk factor for non-Hodgkin lymphoma, which is in-line with the increased risk of HCC after non-Hodgkin lymphoma. The vastly increased risk of HCC after autoimmune diseases, such as autoimmune hepatitis, and a moderate increase in immunosuppressed patients point to the role of immune dysfunction in HCC susceptibility. ${ }^{14,15,27}$ Skin SCC, non-Hodgkin lymphoma and upper aerodigestive tract cancer (including lip and mouth cancers) are hallmark cancers increased in immunosuppressed patients; although kidney and thyroid cancers are not among the hallmark cancers, they are also increased in immunocompromised individuals. ${ }^{28-30}$ Thus, it is likely that immune dysfunction could have contributed to the increased risks of skin SCC, non-Hodgkin lymphoma (together with $\mathrm{HCV}$ ), upper aerodigestive cancer (with alcohol and smoking), kidney cancer and thyroid cancer and to mutual association between hepatobiliary sites (together with surveillance bias). Surveillance bias may potentially contribute to the increase in many SPCs, particularly those in close anatomic proximity. Some studies apply lag time between diagnoses of FPC and SPC to reduce the influence of surveillance. However, as in the Swedish Cancer Registry, practically all cancer diagnoses are histologically verified, lag time would also reduce true cancers and cause another type of bias. ${ }^{31}$

However, we should be careful not to dismiss associations merely because of anatomic proximity, which in the case of hepatobiliary cancers involve, in addition, the pancreas, duodenum (small intestine) and even kidneys through the peritoneum. In the case of hepatobiliary cancers, HCC and gallbladder cancers associated with each other as FPC and SPC, and bile duct cancer associated with gallbladder cancer as SPC; yet no associations were observed between HCC and bile duct cancer. Whether this is due to the fact that the gallbladder is a clear anatomic entity is not known. Cancer cells are known to be able to spread to nearby organs through genetically modified clones or to exert epigenetic suppression. Such bystander effects of "field cancerization" or "cell competition" are known in many organ systems including the liver, gastro-intestinal and urothelial tracts. ${ }^{2,32-34}$ Another mechanism may be local immune suppression of antitumor immune response by activation of FOXP3+ regulatory $\mathrm{T}$ cells, M2 macrophages, CD2 dendritic cells and myeloid-derived suppressor cells. ${ }^{35,36}$ The suppressive environment may extend to nearby organs and prevail over a period of time. ${ }^{37,38}$

Associations of hepatobiliary cancers with small intestinal and pancreatic cancers do not seem to be explainable by known environmental risk factors. For small intestinal cancer, high unidirectional associations were observed with gallbladder and biliary tract cancers but also with HCC. Biliary tract and gallbladder cancers manifest in HNPCC among carriers of the MHL1 mutations, which are the only mismatch repair gene mutations predisposing also to small intestinal and pancreatic cancers. ${ }^{16}$ Thus, HNPCC syndrome may explain the observed associations of these hepatobiliary cancers with small intestinal and pancreatic cancers. Although for the latter, the anatomic proximity to the bile duct may lead to surveillance bias, as suggested by the high risk of the cancers of the ampulla of Vater after pancreatic cancer (for high-grade tumors, histological distinction between the two may be critical). Although colorectal and endometrial cancers are hallmark cancers of HNPCC, they are caused also by mismatch genes other than MHL1, which may be the reason for their lacking association with hepatobiliary cancers. $^{16}$

Bidirectional associations of HCC with kidney and thyroid cancers may have many explanations, in addition to the immune disturbance, discussed above. For kidney cancer, these include metabolic disturbances, and kidney cancer and HCC show the highest cancer risks in type 2 diabetes patients. ${ }^{39}$ Thyroid autoimmune diseases are the most common type of autoimmune diseases in Sweden, accounting for over $10 \%$ of all such diseases. ${ }^{40}$ Hashimoto disease/hypothyroidism is the most common thyroid autoimmune disease and it is associated with a high risk of $\mathrm{HCC} ;{ }^{12}$ however, whether thyroid autoimmunity is a precursor of thyroid cancer is somewhat disputed. $^{41,42}$ Thus there may yet be other reasons; liver cancer is marginally increased in families of patients with nonmedullary thyroid cancer but no associated genes have been identified. $^{43,44}$

The major limitation of the study is the scarcity of data, particularly on rare cancers. The consequence is the generally low precision (wide CIs) of the risk estimates, which warrant caution in conclusions. ${ }^{24}$ Among hepatobiliary cancers, the definition of SPC may not define an independent primary but may be metastasis from another hepatobiliary site. ${ }^{45}$ We had no data on the possible risk factors, such as viral infections, or on personal habits, such as smoking or alcohol consumption. Finally, we have no data on how well SPCs are reported after cancers of poor survival, such as hepatobiliary cancers. Although international comparisons suggest that the reporting is high in Sweden, the present results on breast and prostate cancers with risks below 1.00 may indicate incomplete reporting. $^{20,46}$ The consequence of general underreporting would be underestimation of risks overall. Our foremost strength is having access to high-level cancer registry data. The bidirectional design is another strength both in helping to interpret the associations and to reduce chance findings. Chance findings need to be kept in mind with these kinds of 
studies with numerous comparisons. In the above discussion, biological plausibility was sought to guard against chance findings.

In conclusion, we showed associations of $\mathrm{HCC}$ with cancers of the UAT, esophageal, kidney and bladder cancers and non-Hodgkin lymphoma, most likely explained by shared environmental risk factors. Another group of associated cancers were skin SCC, kidney and thyroid cancers and also non-Hodgkin lymphoma for which immune disturbance may be a contributing mechanism. For the rare gallbladder and bile duct cancers, associations with small intestinal and pancreatic cancers suggest genetic causation through mutations in the mismatch repair gene MLH1. ${ }^{16} \mathrm{HNPCC}$ is increasingly recognized as an important germline risk factor for many cancers, which may be diagnosed as FPCs or SPCs. Detection of mutations in the MLH1 gene should alert the clinician about the rare syndromic cancers of the small intestine, gallbladder and bile ducts.

\section{Statement on Ethics}

The study was approved by the Regional Ethical Review Board in Lund without requirement for informed consent. Instead, the Ethical Review Board obliged us to advertise in the newspapers in order to inform the public that their data would be used for secondary purposes. After that, around 40 individuals were excluded $(\approx 40$ excluded individuals $/ \approx 10$ million individuals in the Swedish population).

\section{Acknowledgments}

We thank Patrick Reilly for excellent language editing. G. $\mathrm{Z}$ is a doctoral student supported by the China Scholarship Council (201606100057).

\section{Author Contributions}

Design: KH, GZ. Acquisition of data: JS, KS. Statistical analysis and interpretation: GZ, KH, AF, AH, TC, VL. Manuscript writing: $\mathrm{KH}$ and all other authors. Approval of the final text: All authors.

\section{Funding}

Supported by the European Union's Horizon 2020 research and innovation programme, grant No 856620 (Chaperon), The Swedish Research Council, Jane and Aatos Erkko Foundation, Sigrid Juselius Foundation, Finnish Cancer Organizations, University of Helsinki and Helsinki University Central Hospital.

\section{Disclosure}

A.H. is a shareholder in Targovax ASA; also is an employee and shareholder in TILT Biotherapeutics Ltd. Other authors declared no conflict of interest.

\section{References}

1. Hamilton S, Aaltonen L, editors. Tumours of the Digestive System. Lyon: IARC; 2000.

2. Villanueva A, Longo DL. Hepatocellular carcinoma. $N$ Engl $J$ Med. 2019;380(15):1450-1462. doi:10.1056/NEJMra1713263

3. IARC. GLOBOCAN 2000. Cancer Incidence, Mortality and Prevalence Worldwide. Lyon: IARC Press; 2001.

4. Yang JD, Hainaut P, Gores GJ, Amadou A, Plymoth A, Roberts LR. A global view of hepatocellular carcinoma: trends, risk, prevention and management. Nat Rev Gastroenterol Hepatol. 2019;16 (10):589-604. doi:10.1038/s41575-019-0186-y

5. Takakura K, Oikawa T, Nakano M, et al. Recent insights into the multiple pathways driving non-alcoholic steatohepatitis-derived hepatocellular carcinoma. Front Oncol. 2019;9:762. doi:10.3389/ fonc. 2019.00762

6. Åberg F, Färkkilä M, Männistö V. Interaction between alcohol use and metabolic risk factors for liver disease: a critical review of epidemiological studies. Alcohol Clin Exp Res. 2020;44 (2):384-403. doi:10.1111/acer.14271

7. Thylur RP, Roy SK, Shrivastava A, LaVeist TA, Shankar S, Srivastava RK. Assessment of risk factors, and racial and ethnic differences in hepatocellular carcinoma. JGH Open. 2020;4 (3):351-359. doi:10.1002/jgh3.12336

8. Rawla P, Sunkara T, Thandra KC, Barsouk A. Epidemiology of gallbladder cancer. Clin Exp Hepatol. 2019;5(2):93-102. doi:10.5114/ceh.2019.85166

9. Bal MM, Ramadwar M, Deodhar K, Shrikhande S. Pathology of gallbladder carcinoma: current understanding and new perspectives. Pathol Oncol Res. 2015;21(3):509-525. doi:10.1007/s12253-014-9886-3

10. Arnold M, Pandeya N, Byrnes G, et al. Global burden of cancer attributable to high body-mass index in 2012: a population-based study. Lancet Oncol. 2015;16(1):36-46. doi:10.1016/S14702045(14)71123-4

11. Hemminki K, Li X. Familial liver and gall bladder cancer: a nationwide epidemiological study from Sweden. Gut. 2003;52:592-596. doi:10.1136/gut.52.4.592

12. Yu MW, Chang HC, Liaw YF, et al. Familial risk of hepatocellular carcinoma among chronic hepatitis B carriers and their relatives. $J$ Natl Cancer Inst. 2000;92(14):1159-1164. doi:10.1093/jnci/ 92.14.1159

13. Petersen G. Familial aggregation: sorting susceptibility from shared environment. J Natl Cancer Inst. 2000;92:1114-1115. doi:10.1093/ jnci/92.14.1114

14. Castro FA, Liu X, Försti A, et al. Increased risk of hepatobiliary cancers after hospitalization for autoimmune disease. Clin Gastroenterol Hepatol. 2014;12(6):1038-1045.e7. doi:10.1016/j. cgh.2013.11.007

15. McGee EE, Castro FA, Engels EA, et al. Associations between autoimmune conditions and hepatobiliary cancer risk among elderly US adults. Int $J$ Cancer. 2019;144(4):707-717. doi:10.1002/ijc.31835

16. Møller P, Seppälä TT, Bernstein I, et al. Cancer risk and survival in path_MMR carriers by gene and gender up to 75 years of age: a report from the prospective lynch syndrome database. Gut. 2018;67(7):1306-1316. doi:10.1136/gutjnl-2017-314057

17. Mousavi SM, Hemminki K. Cancer incidence, trends, and survival among immigrants to Sweden: a population-based study. Eur $J$ Cancer Prev. 2015;24(Suppl 1):S1-S63. doi:10.1097/ CEJ.0000000000000106 
18. Ferlay J, Parkin DM, Steliarova-Foucher E. Estimates of cancer incidence and mortality in Europe in 2008. Eur J Cancer. 2010;46 (4):765-781. doi:10.1016/j.ejca.2009.12.014

19. Travis LB, Demark Wahnefried W, Allan JM, Wood ME, Ng AK. Aetiology, genetics and prevention of secondary neoplasms in adult cancer survivors. Nat Rev Clin Oncol. 2013;10(5):289-301. doi:10.1038/nrclinonc.2013.41

20. Chen T, Fallah M, Jansen L, et al. Distribution and risk of the second discordant primary cancers combined after a specific first primary cancer in German and Swedish cancer registries. Cancer Lett. 2015;369(1):152-166. doi:10.1016/j.canlet.2015.08.014

21. Wu WC, Chen YT, Hwang CY, et al. Second primary cancers in patients with hepatocellular carcinoma: a nationwide cohort study in Taiwan. Liver Int. 2013;33(4):616-623. doi:10.1111/liv.12103

22. Zheng G, Sundquist K, Sundquist J, Försti A, Hemminki A, Hemminki K. Rate differences between first and second primary cancers may outline immune dysfunction as a key risk factor Cancer Med. 2020;9(21):8258-8265.

23. Zheng G, Sundquist K, Sundquist J, Försti A, Hemminki A, Hemminki K. Incidence differences between first primary cancers and second primary cancers following skin squamous cell carcinoma as etiological clues. Clin Epidemiol. 2020;12:857-864. doi:10.2147/ CLEP.S256662

24. Greenland S, Senn SJ, Rothman KJ, et al. Statistical tests, P values, confidence intervals, and power: a guide to misinterpretations. Eur J Epidemiol. 2016;31(4):337-350. doi:10.1007/s10654-016-0149-3

25. Henriksson M, Björnsson B, Sternby Eilard M, et al. Treatment patterns and survival in patients with hepatocellular carcinoma in the Swedish national registry SweLiv. BJS Open. 2020;4 (1):109-117. doi:10.1002/bjs5.50226

26. Ji J, Sundquist K, Sundquist J, Hemminki K. Comparability of cancer identification among death registry, cancer registry and hospital discharge registry. Int $J$ Cancer. 2012;131:2085-2093. doi:10.1002/ ijc. 27462

27. Thomsen H, Li X, Sundquist K, Sundquist J, Försti A, Hemminki K. Familial associations between autoimmune hepatitis and primary biliary cholangitis and other autoimmune diseases. PLoS One. 2020;15(10):e0240794. doi:10.1371/journal.pone.0240794

28. Birkeland S, Storm H, Lamm L, et al. Cancer risk after renal transplantation in the Nordic countries, 1964-1986. Int J Cancer. 1995;60:183-189. doi:10.1002/ijc.2910600209

29. Hortlund M, Arroyo Muhr LS, Storm H, Engholm G, Dillner J, Bzhalava D. Cancer risks after solid organ transplantation and after long-term dialysis. Int $J$ Cancer. 2017;140(5):1091-1101. doi:10.1002/ijc.30531

30. Rama I, Grinyo JM. Malignancy after renal transplantation: the role of immunosuppression. Nat Rev Nephrol. 2010;6(9):511-519. doi:10.1038/nrneph.2010.102

31. Pukkala E, Engholm G, Hojsgaard Schmidt LK, et al. Nordic Cancer Registries - an overview of their procedures and data comparability. Acta Oncol. 2018;57:440-455. doi:10.1080/0284186X.2017.1407039
32. Bernstein $\mathrm{C}$, Bernstein $\mathrm{H}$. Epigenetic reduction of DNA repair in progression to gastrointestinal cancer. World $J$ Gastrointest Oncol. 2015;7(5):30-46. doi:10.4251/wjgo.v7.i5.30

33. Marongiu F, Laconi E. Cell competition in liver carcinogenesis. World J Hepatol. 2020;12(8):475-484. doi:10.4254/wjh.v12.i8.475

34. van Doeveren T, van de Werken HJG, van Riet J, et al. Synchronous and metachronous urothelial carcinoma of the upper urinary tract and the bladder: are they clonally related? A systematic review. Urol Oncol. 2020;38:590-598. doi:10.1016/j.urolonc.2020.01.008

35. Fridman WH, Zitvogel L, Sautes-Fridman C, Kroemer G. The immune contexture in cancer prognosis and treatment. Nat Rev Clin Oncol. 2017;14(12):717-734. doi:10.1038/nrclinonc.2017.101

36. Shalapour S, Karin M. Pas de Deux: control of anti-tumor immunity by cancer-associated inflammation. Immunity. 2019;51(1):15-26. doi:10.1016/j.immuni.2019.06.021

37. Galluzzi L, Vitale I, Warren S, et al. Consensus guidelines for the definition, detection and interpretation of immunogenic cell death. $J$ Immunother Cancer. 2020;8(1):e000337. doi:10.1136/jitc-2019000337

38. Mondino A, Manzo T. To remember or to forget: the role of good and bad memories in adoptive T cell therapy for tumors. Front Immunol. 2020;11:1915. doi:10.3389/fimmu.2020.01915

39. Liu X, Hemminki K, Forsti A, Sundquist K, Sundquist J, Ji J. Cancer risk in patients with type 2 diabetes mellitus and their relatives. Int J Cancer. 2015;137:903-910. doi:10.1002/ijc.29440

40. Thomsen H, Li X, Sundquist K, Sundquist J, Försti A, Hemminki K. Familial risks between Graves disease and Hashimoto thyroiditis and other autoimmune diseases in the population of Sweden. J Transl Autoimmun. 2020;3:100058. doi:10.1016/j.jtauto.2020.100058

41. Chen YK, Lin CL, Chang YJ, et al. Cancer risk in patients with Graves' disease: a nationwide cohort study. Thyroid. 2013;23 (7):879-884. doi:10.1089/thy.2012.0568

42. Dias Lopes NM, Mendonça Lens HH, Armani A, Marinello PC, Cecchini AL. Thyroid cancer and thyroid autoimmune disease: a review of molecular aspects and clinical outcomes. Pathol Res Pract. 2020;216(9):153098. doi:10.1016/j.prp.2020.153098

43. Hińcza K, Kowalik A, Kowalska A. Current knowledge of germline genetic risk factors for the development of non-medullary thyroid cancer. Genes. 2019;10(7):482. doi:10.3390/genes 10070482

44. Hemminki K, Eng C, Chen B. Familial risks for nonmedullary thyroid cancer. J Clin Endocrinol Metab. 2005;90:5747-5753. doi:10.1210/jc.2005-0935

45. Ertel AE, Bentrem D, Abbott DE. Gall bladder cancer. Cancer Treat Res. 2016;168:101-120.

46. Mellemkjaer L, Friis S, Olsen JH, et al. Risk of second cancer among women with breast cancer. Int J Cancer. 2006;118:2285-2292. doi:10.1002/ijc. 21651
Clinical Epidemiology

\section{Publish your work in this journal}

Clinical Epidemiology is an international, peer-reviewed, open access, online journal focusing on disease and drug epidemiology, identification of risk factors and screening procedures to develop optimal preventative initiatives and programs. Specific topics include: diagnosis, prognosis, treatment, screening, prevention, risk factor modification,

Submit your manuscript here: https://www.dovepress.com/clinical-epidemiology-journal systematic reviews, risk \& safety of medical interventions, epidemiology \& biostatistical methods, and evaluation of guidelines, translational medicine, health policies \& economic evaluations. The manuscript management system is completely online and includes a very quick and fair peer-review system, which is all easy to use. 